\title{
SOFRIMENTO E ESPERANÇA: GRUPO DE PACIENTES COM ANOREXIA E BULIMIA NERVOSAS
}

\author{
MISERY AND HOPE: SUPPORT GROUP FOR PATIENTS WITH EATING DISORDERS
}

Manoel Antônio dos Santos

Docente. Bolsista de Produtividade em Pesquisa do CNPq. Departamento de Psicologia e Educação. Faculdade de Filosofia, Ciências e Letras de Ribeirão Preto - USP.

CorrespondênCIA:Av. Bandeirantes, 3900, Bairro Monte Alegre. CEP 14040-901, Ribeirão Preto, SP. masantos@ffclrp.usp.br Telefone: (16) 3602-3645

Santos MA. Sofrimento e esperança: grupo de pacientes com anorexia e bulimia nervosas. Medicina (Ribeirão Preto) 2006; 39 (3): 386-401.

RESUMO: O autor apresenta sua experiência como psicoterapeuta de um grupo de pacientes diagnosticados com anorexia e bulimia nervosas. Esse grupo se insere em um serviço especializado de assistência de caráter interdisciplinar existente desde 1982 no HC-FMRP-USP. O grupo é aberto a pacientes com transtornos alimentares de ambos os sexos, predominando mulheres jovens, solteiras, de procedência socioeconômica diversificada. As formulações psicodinâmicas são empregadas na fundamentação teórico-clínica da intervenção. O não reconhecimento da condição psicopatológica, as comorbidades psiquiátricas e o sentimento de desconfiança nos relacionamentos humanos constituem os desafios terapêuticos a serem vencidos com vistas à formação de uma aliança terapêutica entre pacientes e profissionais de saúde. Nesse sentido, a intervenção psicológica almeja sensibilizar esses pacientes quanto à necessidade de se tratarem, buscando desenvolver a consciência sobre o problema e uma atitude responsável em relação ao atendimento. O apoio oferecido, além de sua dimensão socioemocional, tem uma faceta educativa. O processo terapêutico em grupo parece facilitar a construção de condições favoráveis à mudança, sustentando um espaço de troca de experiências e de atitudes de mútua ajuda que aumentam o senso de união e coesão grupal. Nesse sentido, a experiência acumulada nos últimos anos tem demonstrado que o grupo de pares promove a ressignificação de crenças, valores e sentimentos relacionados ao próprio corpo e ao processo de auto-cuidado, com reflexos positivos na redução dos sintomas que comprometem a esfera oroalimentar. Concluindo, sustenta-se que a condução da psicoterapia nesse contexto deve priorizar o restabelecimento do vínculo primordial com a vida.

Descritores: Anorexia Nervosa. Bulimia Nervosa. Psicoterapia de Grupo - Apoio.

\section{1- TRANSTORNOS ALIMENTARES: ABOR- DAGEM MULTI E INTERDISCIPLINAR}

No presente trabalho buscamos relatar nossa experiência com pacientes atendidos junto a um programa de assistência multidisciplinar denominado GRATA - Grupo de Assistência em Transtornos Alimentares. Trata-se de um programa implantado há alguns anos dentro de um serviço especializado que funciona desde 1982 junto ao Ambulatório de Nutrologia do Hospital das Clínicas da Faculdade de Medicina de Ribeirão Preto da Universidade de São Paulo.

As intervenções oferecidas são pautadas em uma filosofia de trabalho interdisciplinar. A equipe de saúde é constituída por médicos nutrólogos, nutricionistas, psicólogos, psiquiatras, enfermeiros e estagiá- 
rios do curso de graduação em Psicologia. São atendidos pacientes diagnosticados com anorexia nervosa (AN) e bulimia nervosa (BN). É importante salientar que, em nossa compreensão, categorias nosológicas correspondem a nomes genéricos que designam diagnósticos de diversas psicopatologias que guardam entre si algumas semelhanças, porém também têm formas de apresentação, evolução e prognósticos diferentes. Por isso cada caso merece uma atenção particular e exige um plano de tratamento personalizado.

A clínica dos transtornos alimentares configura um campo de alta densidade da experiência vivida, dado o nível de comprometimento de áreas vitais implicadas. Além dos prejuízos físicos evidentes, os pacientes apresentam graves alterações do funcionamento psicossocial, que se expressam tanto no plano da personalidade quanto do comportamento. Como traços característicos dos portadores desses transtornos figuram: o isolamento social, implicando na deterioração da qualidade e regularidade das relações sociais, o humor depressivo, a invasão dos afetos desorganizando o funcionamento intelectual, com prejuízos marcantes na adaptação e qualidade de vida ${ }^{1,2}$.

O medo de morrer é universal e atinge todos os seres humanos ${ }^{3}$. No entanto, pacientes anoréxicos e bulímicos colocam em risco a própria vida. Mesmo quando se vêem diante da possibilidade concreta de morrerem, agem como se desdenhassem da morte, manifestando uma notável indiferença, freqüentemente mesclada com uma sensação de triunfo maníaco, que na verdade é reflexo da extrema dissociação entre pensamento e afeto que os acomete.

Na etapa da vida (adolescência) em que se encontra a maioria dos pacientes com transtornos alimentares, eles podem vivenciar mortes concretas de parentes, amigos ou pessoas conhecidas. No entanto, de maneira um tanto quanto dissociada, esses jovens vivem a desafiar a morte porque, em seu pensamento, ela é um fenômeno distante e inconcebível. Decorre daí o engajamento em inúmeros comportamentos de risco: além dos sintomas característicos do transtorno alimentar, apresentam diversas morbidades psiquiátricas associadas, tais como abuso de álcool e outras drogas, tentativas de suicídio, promiscuidade sexual, exposição a acidentes (no caso dos rapazes: os denominados "rachas", o engajamento em esportes radicais), que são defesas contra a ansiedade diante da morte.

$\mathrm{Na}$ doença somática, diferentemente do que ocorre na AN e BN, o paciente sente-se ameaçado em sua integridade física. Morrer é evento evidente- mente aversivo para todos nós, mas a julgar pelos comportamentos de risco a que se entrega o paciente com transtornos alimentares, essa máxima universal nem sempre é válida. Muitas vezes o paciente formula expressamente seu desejo de morrer, enquanto que, para aquele que vivencia uma doença orgânica potencialmente letal, o simples pensar na possibilidade da morte causa sofrimento devido à tomada de consciência de sua finitude, que o obriga a estabelecer prioridades, revisar projetos de vida e reavaliar os valores que governam sua existência. Em nossa experiência clínica, pacientes com câncer, por exemplo, de alguma forma estão cientes de seu estado de saúde, ou seja, têm consciência de que vivem uma condição-limite e limitante, embora freqüentemente evitem falar sobre isso, demonstrando o quanto lhes é doloroso tanger essa questão. Esse comportamento evitativo depende, evidentemente, do estágio em que se encontram do processo de ajustamento à enfermidade (negação e isolamento, raiva, barganha, depressão ou aceitação/resignação).

É impressionante o quanto à possibilidade da morte parece não se constituir como problema para anoréxicos e bulímicos, na medida em que dão a entender que não acreditam que podem de fato morrer, muito embora a morte seja uma experiência universal. Possivelmente porque não experimentam a vida em sua plenitude, afinal: "Quando se aprende a morrer, aprende-se a viver" (p. 84) ${ }^{4}$.

Não ser capaz de reconhecer no seu comportamento alimentar um traço patológico é o maior desafio terapêutico a ser vencido, na medida em que dificulta ou até mesmo inviabiliza o desenvolvimento de uma aliança terapêutica entre o profissional de saúde e o paciente ${ }^{5}$.

Nesse sentido, a intervenção psicológica almeja levá-los, primordialmente, a reconhecerem que a vida (assim como a morte, no caso dos pacientes somáticos portadores de doenças fatais) precisa ser cuidada. O processo terapêutico é importante para facilitar a possibilidade da mudança, que advém da ressignificação de valores, crenças e sentimentos relacionados ao próprio corpo e ao processo de autocuidado. O doente, de um modo geral, sente necessidade de atribuir um significado para sua doença e tratamento e, dentre os múltiplos sentidos possíveis, pode incluir (ou não) o medo da morte. Na AN/BN, contudo, o que parece prevalecer é o medo da vida.

Acreditamos que, no caso do paciente anoréxico/bulímico, é preciso levá-lo a compreender que há 
vida antes da morte. Ou seja, a condução de uma psicoterapia nesse contexto vai priorizar o restabelecimento do vínculo primordial com a vida, que se encontra comprometido nesses pacientes. Uma advertência, principalmente para o terapeuta mais afoito, é que o mais importante, nesses casos, é não cair na tentação de estabelecer um padrão-ouro para a assistência, mas saber respeitar o tempo e o ritmo das necessidades de cada paciente. Há momentos em que o paciente está mais debilitado, com as defesas físicas e psíquicas desorganizadas, ao passo que em outros se mostra mais integrado e receptivo à ajuda. Nesse caso é preciso esperar pacientemente os momentos oportunos, entendendo que no plano psicológico tudo tem sua hora e sua vez.

A literatura sugere que o tratamento ajuda a minimizar o sofrimento psicológico e a melhorar a qualidade de vida dos pacientes e seus familiares. Diante de uma enfermidade multifatorial como são os transtornos alimentares, é preciso oferece oportunidade aos pacientes para expressarem seus sentimentos e emoções. Eles exigem um apoio especial, direcionado sobretudo para as questões que o transtorno desencadeia. Esse apoio tem uma faceta educativa (necessidade de prover informações relacionadas ao transtorno e esclarecimento de dúvidas em relação a aspectos do tratamento, tais como recomendações nutricionais, exames e procedimentos médicos, necessidade de hospitalização em determinados casos) e uma faceta sócioemocional (possibilidade de ventilar as angústias despertadas pelas restrições e alterações bruscas que se impõem no cotidiano e na vida familiar).

\section{2- GRUPO DE PACIENTES COM AN E BN: PILARES DE SUSTENTAÇÃO}

Nossa experiência com pacientes atendidos junto ao GRATA está alicerçada nos seguintes eixos organizadores:

Coordenação: psicólogo e psicóloga (co-coordenadora); havendo ainda um(a) estagiário(a) de Psicologia no papel de observador silente.

Número de participantes: variável (em média seis por sessão, com uma amplitude de variação nos últimos três anos entre quatro e quatorze pacientes).

Freqüência: uma sessão semanal.

Duração das sessões: 90 minutos.

Local: sala de grupo nas instalações do HCFMRP-USP.
Dia e horário: até dezembro de 2005 o grupo funcionou às terças-feiras, das $7 \mathrm{~h} 30 \mathrm{~m}$ às $9 \mathrm{~h} 00$. A partir de janeiro de $2006 \mathrm{o}$ atendimento deslocou-se para as sextas-feiras, das $12 \mathrm{~h} 00$ às $13 \mathrm{~h} 30 \mathrm{~m}$.

Seleção de integrantes: entrevista individual e/ou psicodiagnóstico na admissão do paciente.

\section{Critérios de inclusão para o grupo}

- Diagnóstico: são considerados elegíveis pacientes que preenchem os critérios diagnósticos do DSM-IV para AN e BN;

- Idade: faixa etária a partir de 14 anos, sem limite máximo;

- Aceitação: aquiescência, por parte dos participantes, das características de funcionamento do grupo e de uma modalidade específica de trabalho com os aspectos emocionais associados aos transtornos (portanto, um trabalho com a "mente" e não que tenha como foco o corpo e os aspectos médicos/nutricionais da enfermidade);

- Disponibilidade: para comparecer ao grupo pelo menos no dia dos retornos médicos (o que implica, sempre que possível, na disponibilidade de comparecer ao hospital uma vez por semana, independentemente de haver ou não retorno médico).

\section{Critérios de exclusão para o grupo}

- presença de morbidade psiquiátrica (quadro agudo);

- dificuldades de ordem pessoal (rebaixamento intelectual, sintomas psicóticos, problemas de comunicação verbal ou acuidade auditiva) que podem contraindicar o encaminhamento do paciente para grupo.

Partimos do pressuposto de que oferecer a possibilidade do encontro cria o espaço terapêutico, a partir do intercâmbio e da ajuda mútua. A reunião proporciona a experiência empírica de uma situação análoga à vivência familiar, onde há a confrontação de semelhanças e diferenças convivendo no mesmo espaço.

A troca de experiências entre pessoas que compartilham problemas semelhantes e que têm os mesmos objetivos possibilita discutir situações vivenciadas com o adoecimento e o tratamento ${ }^{6}$. Com a ajuda dos terapeutas, os participantes podem se permitir refletir sobre suas emoções e condutas, a partir de um novo e diferente vértice que é gerado pelas interações no grupo, criando, desse modo, uma maior possibilidade de mudança em seus padrões relacionais. 


\section{3- OS ANDAIMES DO GRUPO: DO APOIO AO TERAPÊUTICO}

Do ponto de vista da estratégia empregada para a condução do contexto grupal, existem diferentes modalidades de grupo, desde os grupos de sala de espera, dispositivos abertos que geralmente reúnem pacientes e familiares, até os grupos psicoterapêuticos. Os grupos podem ainda ser eminentemente educativos ou mistos (psicoeducativos). Vale lembrar que:

É válido partir do princípio de que, virtualmente, a essência dos fenômenos grupais é a mesma em qualquer tipo de grupo, e o que determina óbvias diferenças entre os distintos grupos é a finalidade para a qual eles foram criados e compostos. (...) É amplo o leque de aplicações da dinâmica grupal, vasta a possibilidade de fazer arranjos combinatórios criativos entre seus recursos técnicos e táticos, e, igualmente, há uma certa confusão semântica na área da grupalidade. (p. 75) ${ }^{7}$.

Na modalidade denominada "de espera", que ocorre em instituições de saúde, geralmente os participantes não vieram ao serviço para o grupo, mas a equipe oferece a possibilidade de ocupar o tempo ocioso de espera das consultas. Esses grupos são geralmente abertos, com alta rotatividade de pacientes, de tal modo que a composição de participantes é única e dificilmente se repete em uma nova edição. O coordenador não se encontra toda semana com os mesmos pacientes, mas trabalha com os que estão reunidos naquele dado momento e que tenham interesse em conversar com profissionais e outros pacientes e/ou seus acompanhantes.

Em nossa prática ambulatorial junto ao GRATA os grupos são abertos, o que significa dizer que os participantes são livres para comparecem semanalmente, prescindindo de agendamento prévio - tal como ocorre com os retornos regulares às modalidades individuais de assistência que são oferecidas pelo ambulatório. No caso das chamadas síndromes psicossomáticas, como é o caso dos transtornos alimentares, observa-se que o atendimento psicológico a princípio não se enquadra exatamente na demanda do paciente, cujo interesse prioritário manifesto é a consulta com o médico nutrólogo e a nutricionista. Além disso, alguns pacientes que aceitam o encaminhamento para psicoterapia individual são atendidos fora do dia do ambulatório. Nos primórdios do atendimento o paciente com anorexia ou bulimia está centrado nos sintomas físicos, e só mais secundariamente se mostra interessado nas questões psicológicas, dada a ausência de uma clara percepção da influência de fatores afetivo-emocionais sobre suas manifestações sintomáticas.

De modo análogo ao que ocorre nos grupos de apoio realizados em contextos de tratamento de alguma enfermidade orgânica, que congregam pacientes que não acorrem à instituição primariamente para tratar de seus aspectos psicológicos, nos transtornos alimentares freqüentemente deparamos com pacientes que não reconhecem que sua condição de sofrimento tem também uma faceta psicológica. Além de, como referido anteriormente, em muitos casos os pacientes negarem sua condição de pessoas que necessitam de ajuda. Costumamos dizer que esses pacientes ainda precisam ser "apresentados" ao seu mundo mental, que eventualmente desconhecem e em relação ao qual têm profundo receio de se aproximarem.

É bem conhecido que portadores de quadros orgânicos também apresentam resistência à abordagem psicológica. Quando o sofrimento se inscreve no corpo, mas suas raízes repousam nas profundezas do psiquismo, podemos imaginar que as coisas sejam mais fáceis, mas não é bem assim que acontece. Em enfermidades como anorexia e bulimia, a resistência ao tratamento é uma constante, sobretudo no início, quando o vínculo ainda não está bem estabelecido. É uma constatação comum na prática assistencial que esses pacientes apresentam um insight muito pobre dos problemas que os afligem.

Normalmente, na sala de espera das instituições de saúde as pessoas sentam-se umas ao lado das outras e, espontaneamente, comentam aspectos de sua vida. A idéia de oferecer um grupo é formalizar esse espaço informal de interação, onde as pessoas possam aproveitar de um modo mais eficiente suas potencialidades, organizando respostas de enfrentamento diante das adversidades que explorem o potencial curativo do apoio mútuo que o grupo é capaz de promover.

As estratégias grupais de apoio circunscrevem um espaço permissivo e seguro para a expressão emocional, bem como para a troca de experiências entre os membros do grupo, que compartilham situações vitais semelhantes decorrentes do enfrentamento de uma problemática semelhante. Por essa razão, os grupos costumam ser divididos por quadros clínicos, de modo que a população beneficiada freqüentemente é homogênea em relação ao critério do diagnóstico, mas não necessariamente da idade, sexo e outros atributos físicos, sociais ou culturais. 
O objetivo da estratégia grupal é justamente tirar proveito dessa situação de um certo nível de heterogeneidade na relativa homogeneidade. Explora-se o potencial terapêutico do encontro das diferenças individuais (pluralidade de experiências) em um contexto de relativa homogeneidade, garantida - mas só até certo ponto - pelo diagnóstico comum.

Podem ser evocados três princípios básicos para a compreensão do funcionamento do apoio mútuo ("mútua ajuda"): homogeneidade, modelização e confrontação ${ }^{8}$. As táticas de intervenção utilizadas no grupo de portadores de AN e BN aproximam-se, em seus fundamentos técnicos, das estratégias descritas no contexto das psicoterapias de apoio (ou de esclarecimento). Assim, as intervenções podem ser: explorativas, informativas e integrativas?

Explorativas: correspondem às intervenções que buscam investigar o que o paciente conhece a respeito do transtorno alimentar e de seu tratamento. Incentivamos cada membro do grupo a explanar livremente sobre suas concepções, idéias e sentimentos, ficando atentos à maneira como cada um consegue subjetivar suas questões.

Informativas: visam proporcionar a disseminação de conhecimentos atualizados sobre o transtorno, mediante uma linguagem compatível e adaptada ao nível sociocultural do paciente.

Integrativas: almejam o desenvolvimento de habilidades de elaboração das situações vivenciadas e a aprendizagem através da experiência (própria e do outro que vivencia uma situação semelhante em seu contexto de vida).

Outras estratégias de apoio utilizadas compreendem: a clarificação, a confrontação e a orientação.

Clarificação: procura-se facilitar o reconhecimento dos recursos de enfrentamento que cada paciente utiliza para fazer frente à crise vital provocada pela enfermidade ou pelas seqüelas eventualmente produzidas por sua cronicidade.

Confrontação: o grupo gera a necessidade de que os participantes coloquem à prova a sua subjetividade e confrontem o que sentem com os dados objetivos provenientes da realidade biológica, psicológica e social. A realidade física/concreta do corpo esquelético do anoréxico "grita" na confrontação com a negação psicológica da gravidade dos seus sintomas. O mesmo ocorre com a descrição, freqüentemente neutra do ponto de vista emocional, que o bulímico faz de suas manobras purgativas, como vomitar mais de vinte vezes em um único dia ou tomar cartelas inteiras de comprimidos de laxantes e diuréticos.
Orientação: visa prover apoio emocional para um manejo mais adequado dos conflitos intrapsíquicos. O terapeuta apenas leva em consideração os aspectos psicodinâmicos inconscientes, sem contudo interpretá-los no contexto da sessão.

É importante ressaltar que essas intervenções não são prerrogativas da dupla de terapeutas. Podem ser oferecidas a qualquer hora por qualquer participante do grupo. Aliás, como ficará mais evidente quando analisarmos as interações grupais, na maioria das vezes são os próprios pacientes que se encarregam de conduzir o processo grupal, e de certo modo praticamente detém o monopólio da palavra.

Via de regra, no grupo procuramos estimular intervenções que promovam a auto-revelação do paciente do paciente em termos de suas vivências afetivas presentes naquele momento de sua vida ${ }^{10}$. $\mathrm{O}$ foco da intervenção é a relação com os sintomas que ele apresenta e que justificam a busca de tratamento.

A descrição de sentimentos relacionados à doença e ao tratamento contribui para a subjetivação dos sintomas e uma apropriação pessoal dos recursos de enfrentamento. Ao encontrar um ambiente de confiança e respeito, cada integrante do grupo tem a oportunidade de exercitar suas forças curativas, tanto ao receber, quanto ao oferecer apoio. Nessa medida, é possível alcançar um outro objetivo muito caro a esses grupos, que é o de fortalecer a vinculação ao tratamento como um todo, incluindo todas as formas de intervenção oferecidas pela equipe, sem uma hierarquização.

Os esforços envidados devem ser devidamente valorizados para que o paciente perceba que o investimento que está fazendo não é em vão e que, em última instância, é em prol de seu autocuidado. Estratégias de enfrentamento que promovam confronto positivo com a doença são encorajadas, assim como se estimula a comunicação o mais franca e aberta possível com a equipe de saúde.

Na condução do grupo, os coordenadores buscam desenvolver em cada participante uma atitude de participação ativa no processo de tratamento. Os pacientes são encorajados a buscarem padrões menos regredidos de comportamento. A abordagem grupal favorece essa transformação, uma vez que se propõe a tratar o indivíduo em situação, em vez de isolá-lo de seu contexto social e interacional.

Na situação grupal há uma produção coletiva de significados, que podem ser explorados e canalizados na busca de soluções para os problemas comuns que afetam o cotidiano de todos. Com essas diretrizes 
em mente, o coordenador do grupo busca estimular a recuperação física e emocional do paciente. Desse modo se almeja reforçar sua auto-estima, atenuando o impacto de uma auto-imagem normalmente comprometida na presença da enfermidade. Reconhecese, normalmente, a distorção da imagem corporal como um sintoma distintivo dos quadros de transtorno alimentar, especialmente na anorexia nervosa.

O paciente psicossomático pede para que olhemos para sua pessoa e seu intenso sofrimento psíquico situando sua dor nos confins do corpo. Em última análise, endereça ao profissional de saúde o clamor silencioso de um psicossoma mal integrado. Necessita ser acolhido para que se sinta legitimado em sua dor. Por isso precisamos oferecer uma estratégia de apoio que contemple as múltiplas demandas que escolhem a vertente somática como via privilegiada de expressão da dor psíquica.

$\mathrm{O}$ terapeuta comumente assume uma postura ativa nesse tipo de atendimento. Essa atividade que marca a conduta do terapeuta transparece ao se privilegiarem alguns temas, dos tantos que surgem espontaneamente do próprio grupo, uma vez que não trabalhamos com agenda de assuntos pré-estabelecidos. Cabe aos próprios participantes introduzirem o que desejam discutir em cada reunião. Porém o coordenador reforça positivamente quando aparecem espontaneamente temas que indicam enfrentamento positivo, bem como estimula o compartilhamento de emoções e a oferta de apoio para aqueles que manifestam dificuldades de lidar com as dificuldades vivenciadas no cotidiano.

Uma outra tarefa que cabe ao terapeuta desempenhar é distribuir a palavra. Com isso, procura dar voz a todos, bem como estimular pessoas que se mostram mais tímidas e silentes. Também é importante conter os mais entusiasmados, que por serem naturalmente mais falantes podem inibir a expressão verbal dos membros menos descontraídos. É também tarefa do terapeuta equilibrar os pontos de vista entre os diversos participantes, de maneira a permitir que a diversidade de opiniões apareça, dentro de um clima de tolerância e respeito às divergências. Afinal, quando as diferenças podem ser acolhidas e respeitadas, todos os integrantes do grupo saem enriquecidos.

Frequientemente temos testemunhado relatos de pacientes que comentam que essa experiência de contato informal é extremamente favorável. Apesar de estarem na maior parte do tempo imersas em um mundo hermeticamente fechado, anoréxicos e bulími- cos são sensíveis à dor alheia e se interessam genuinamente pelo sofrimento dos outros membros do grupo. Isso talvez possa ser explicado pela montante de sofrimento emocional que vivenciam, levando ao desenvolvimento da compaixão (palavra que etimologicamente designa a capacidade de estar ao lado do outro que sofre). Como afirmou o paciente enfermo retratado no livro A última lição ${ }^{4}$ : "Agora que estou sofrendo, sinto-me mais perto de pessoas que sofrem do que sentia antes". (p. 55)

Alguns pacientes, evidentemente, mostram resistências e dificuldades de se adaptarem ao formato do grupo, mas com o passar do tempo observamos que os membros mais reservados começam a se descontrair e interagir melhor nessa situação. Em três anos de atendimento semanal nunca ouvimos um paciente relatar que não se interessava por saber o que o outro tinha. Muito pelo contrário, estabelece-se rapidamente uma aliança de trabalho, tanto tácita como explícita, entre os pacientes, que manifestam agudo interesse e se preocupam ativamente, por exemplo, com aqueles que precisam ser hospitalizados em função de um eventual agravamento do quadro, assim como vibram entusiasticamente quando alguém recebe alta. (Posteriormente, traremos uma vinheta clínica que ilustra essa situação.)

Desse modo, um dos objetivos cruciais do grupo é auxiliar o paciente a identificar e expressar suas necessidades emocionais e organizar seus pensamentos de modo a tornar significativa a experiência afetiva. Poder apoiar-se no outro - e até certo ponto espelharse nos outros pacientes - pode ser um meio bastante eficiente de manter a esperança e a confiança na própria mudança.

A experiência de compartilhar emoções também produz um efeito catártico ${ }^{11 / 15}$. Em anos de experiência acumulada nunca ouvimos alguém dizer que é muito ruim falar sobre determinado assunto, mesmo quando descrevem experiências de alta densidade emocional.

Alguns autores costumam dizer que, no caso de grupo terapêutico, geralmente o terapeuta é menos ativo, pois precisa deixar surgir à transferência para que possa trabalhar - o que exige, por outro lado, um maior nível de tolerância à ansiedade $7,10,16,17,18$.

Em nossa experiência a linha que separa o grupo de apoio e o grupo terapêutico é muito tênue, e talvez seja apenas uma questão de ênfase. Detalhando melhor nosso pensamento, alicerçado em uma prática continuada de anos a fio ${ }^{19 / 22}$ : em determinada reu- 
nião, com uma configuração específica de pacientes e forças psíquicas em jogo na arena grupal, o espaço funciona mais como grupo de apoio; os pacientes estão mais fragilizados e é necessário focalizar: "Como é para você fazer o tratamento aqui?" Noutras ocasiões, porém, o espaço funciona plenamente como um grupo terapêutico, com ênfase sobre os conteúdos psíquicos vivenciados no aqui e agora, focalizando-se, por exemplo: Qual era seu estado emocional quando você veio para cá hoje? E agora, mudou algo ou permanece igual?"

No grupo de apoio entendemos que o vínculo entre os pacientes é mais tênue, o que influencia no conteúdo emocional que emerge (temas menos densos e conflitivos, menos carregados de carga afetiva). Uma outra característica da modalidade de apoio é que perdura no contexto grupal certa heterogeneidade, que implica certas limitações no aprofundamento do vínculo estabelecido entre os diversos componentes do grupo. Afinal de contas, são pacientes de várias idades, gêneros, diversos estágios de evolução da enfermidade, que se encontram em diferentes estágios do tratamento.

No início da implantação do dispositivo grupal deparamos com uma preocupação da equipe de saúde com o fato de que agrupamos pacientes que estavam melhorando com aqueles que apresentavam piora ou muitas intercorrências em seu processo de tratamento. A pergunta que se coloca freqüentemente nessa situação é: será que o contato com os pacientes em estado grave não poderia prejudicar os que estão em condição de franca melhora? A prática se encarregou de nos mostrar que isso raramente acontece. $\mathrm{O}$ que se observa empiricamente é que o paciente que está melhor se sente bem ao trazer sua experiência com conotação de superação ("Eu já passei por isso...”), pois essa afirmação reforça a idéia de que ele melhorou, que não está mais como aquele outro que não melhorou. Já o paciente que se encontra em estado grave, por sua vez, acaba se beneficiando do contato com aquele que supostamente está bem, pois sente que, se este pôde, também ele poderá um dia alcançar esse resultado favorável.

Com a aplicação do grupo pretendemos, ainda, alcançar outros objetivos, dentre os quais podemos destacar:

1. Propiciar um contexto confiável em que o paciente possa adquirir habilidades para lidar com a ansiedade e novos recursos de enfrentamento, de modo a obter um melhor manejo de ansiedades e novos modos de resolução de conflitos, que se reflitam em situações vividas no dia-a-dia.

2. Incentivar o exercício da ajuda mútua por meio da partilha, no contexto do grupo, de problemas similares.

3. Estimular novas formas de lidar com o conflito gerado pela necessidade de dependência versus temor da perda de autonomia.

4. Buscar desfechos mais satisfatórios para suas histórias de dor e sofrimento

5. Ajudar o paciente a ter menos medo do futuro, encorajando seus movimentos no sentido do crescimento e da gradual individuação.

Temos consciência de que nosso trabalho é apenas parte de uma estratégia mais ampla que almeja alcançar o processo de humanização do tratamento. Nesse sentido, a família também é incluída como parceira e, ao mesmo tempo, beneficiária da assistência. Assim, o eixo norteador da terapêutica é o reconhecimento da unidade paciente-família.

\section{4- GRUPO: METAMORFOSES EM CONS- TRUÇÃO}

Julgamos interessante ilustrar alguns dos pressupostos teóricos que declinamos anteriormente por meio de uma análise de conteúdo de uma sessão de grupoterapia. Longe de buscarmos exaurir esses conteúdos e suas múltiplas possibilidades de interpretação, nosso intuito aqui é permitir uma aproximação do leitor com os conteúdos que constituem o campo de sentidos negociados por esses pacientes no contexto grupal.

Empreendemos uma análise de conteúdo temática a partir de registros audiogravados, mediante consentimento expresso por meio de assinatura de um termo de consentimento livre e esclarecido. Essa análise permitiu destacar as seguintes unidades de significado:

\section{1- O paciente na relação consigo mesmo (al- terações que vivencia na sua experiência atual)}

a) Início do transtorno

- Os relatos remontam à experiência de conviver no dia-a-dia com as limitações trazidas pelo transtorno alimentar. A restrição das potencialidades existenciais é uma característica saliente nos relatos dos pacientes ${ }^{23}$. 
- Os pacientes utilizam o espaço do grupo para retomarem relatos de como surgiu o problema [em geral, um aparecimento muito lento, insidioso; a negação do quadro, quando o transtorno é finalmente diagnosticado; os sentimentos ambivalentes em relação ao tratamento; a construção progressiva da consciência da "doença" e a aceitação do tratamento ou de parte dele].

- Busca de novos sentidos para o adoecer e o tratamento.

\section{b) Sentimento de vulnerabilidade pessoal}

- Sentimento de estar acometido por forças incontroláveis (a compulsão alimentar, no caso dos bulímicos; o medo do descontrole sobre a conduta alimentar, no caso dos anoréxicos); sentimento de ser dominado pelos sintomas, de permanecer hospitalizado e perder seu senso pessoal de autonomia, tornando-se totalmente dependente do outro e à mercê dos cuidados médicos.

c) Repercussões do transtorno e do tratamento

- Isolamento social: o grupo emerge como oportunidade de socialização e busca de aceitação social.

- Preparo para exames e internações, sujeição a procedimentos médicos invasivos são temas muito ventilados no grupo. Relatam a vivência amedrontadora de ter o próprio corpo examinado, perscrutado, dissecado, vasculhado, vigiado e controlado por agentes externos.

- Viagens, deslocamentos freqüentes da cidade de origem para o tratamento ambulatorial que é realizado no hospital: tratar-se também implica em ampliar o horizonte de vida para os pacientes. Há toda uma história anterior de busca de ajuda e suporte profissional, configurando verdadeiras peregrinações por várias instituições e agentes de cura.

- Necessidade de administrar a vida doméstica: o tratamento absorve tempo e energia, constituindo uma tarefa complexa e estressante também para a família, sobrecarregando em especial os cuidadores.

4.2- O paciente na relação com o outro (alterações no contato social, empobrecimento das relações interpessoais e da rede social de apoio)

a) Com a família: vivências de superproteção alternadas com experiências de abandono e desamparo; cerceamento da liberdade pessoal, gerando reações de irritação; essas experiências vividas no contexto dos relacionamentos familiares acen- tuam a questão da dependência, aumentando a preocupação do paciente com suas limitações. Uma paciente se queixa, por exemplo, que quando dorme um pouco mais, a mãe se angustia e aproxima-se dela para ver se ela ainda está respirando, imaginando que ela morrera dormindo.

b) Com pessoas do círculo externo à família: sentimento de ser diferente, de ser socialmente discriminado e estigmatizado, o que leva a evitar estar no meio de outras pessoas. Já no grupo o desconforto é mitigado, pois sentem que estão entre iguais e se sentem compreendidos.

\section{3- O paciente, sua família e o tratamento}

Em estudos anteriores focalizamos a família dos portadores de $\mathrm{AN}$ e $\mathrm{BN}^{24,25,26}$. Mostramos que o mesmo comportamento de cuidado dos pais é o que pode se encaminhar para a superproteção obsessiva e o sufocamento dos movimentos de busca de independência e autonomia, levando à infantilização do filho, que freqüentemente se sente diminuído e desacreditado em seu potencial de desenvolvimento.

Por essa razão o tratamento precisa:

a) Considerar também os riscos que rondam o cuidador. Os familiares também sofrem o desgaste com a intensa sobrecarga física e emocional resultante do cuidar. E os pacientes, por sua vez, necessitam de estratégias específicas para lidar com perdas (capacidade funcional, competência profissional, senso de auto-eficácia), que têm implicações diretas em sua qualidade de vida.

b) Integrar a família dentro de um programa terapêutico, visando efetivamente uma assistência integral.

c) Auxiliar os familiares no manejo dos sintomas e dificuldades dos pacientes, trabalhando com o desenvolvimento de recursos, evitando uma ênfase excessiva nos déficits, nas dificuldades e nos pontos de estagnação do desenvolvimento emocional.

d) Ajudar os familiares a elaborar o impacto de uma doença crônica grave sobre a visão de mundo e a concepção que se tem da vida, de modo a adquirir representações mais amadurecidas sobre a enfermidade, seus riscos e possibilidades de superação.

Por se tratar de uma enfermidade crônica, enquanto membros da equipe de saúde estamos preocupados com o controle dos sintomas, reconhecendo que nem sempre é possível alcançar a remissão completa. Por isso é importante que os familiares e pacientes percebam que temos como ajudá-los a obter respostas para algumas de suas dúvidas e que dispomos de recursos eficazes para lidar com suas inquietações. 


\section{5- ILUSTRAÇÃO CLÍNICA}

Na sessão em foco*, ocorrida em 27 de janeiro de 2004, o grupo estava constituído por sete pacientes do sexo feminino, sendo seis com quadro de AN (cinco do tipo purgativo, uma do tipo restritivo) e uma portadora de BN. As pacientes conversavam sobre o acolhimento das novas pacientes: Vi e V., esta última recém-chegada ao serviço, já em estado muito grave, a ponto de ter sido imediatamente internada.

Composição do grupo na sessão em foco (todas do sexo feminino) e seus respectivos diagnósticos

V. - anorexia nervosa do tipo purgativo; presente pela segunda vez no grupo, agora na condição de paciente hospitalizada; apresenta-se na sessão com vestes hospitalares; seu estado de debilidade física e emagrecimento extremo, juntamente com a sonda nasogástrica que usa, causam forte impacto no início do grupo.

Vi. - bulimia nervosa, participa pela primeira vez no grupo.

K. - anorexia do tipo purgativo (ou seja, com restrição alimentar alternada com episódios purgativos).

G. - anorexia nervosa do tipo purgativo; é deficiente visual, usa óculos escuros e está se preparando para uma possível hospitalização para realização de um procedimento cirúrgico.

C. - anorexia nervosa do tipo purgativo.

B. - anorexia nervosa do tipo restritivo e transtorno obsessivo-compulsivo associado.

D. - anorexia nervosa do tipo purgativo.

No movimento de abertura do grupo processou-se a seguinte seqüência interacional:

K. - Mas o grupo tá melhor, se for ver. Todo mundo acho que tá se recuperando. Tem os altos e baixos, mas todo mundo tá se recuperando bem. (...)

C. - A gente faz isso [ou seja, instila esperança] com quem tá chegando. [Risos]

K. - É, porque nós precisamos mesmo do grupo.

Terapeuta - E de acolhimento. Como vocês estão fazendo agora: todo o grupo tentando acolher a V. e deixá-la mais confortável nesse grupo.

C. - É, a gente ficou preocupada o dia que ela chegou, né, porque assim, era muito difícil assim ver você chegando. Cê tava chorando, parecia que cê não queria ficar, sei lá.

K. - Mesmo porque se você nunca passou por essa fase, ninguém entende. Já a gente entende! Uma entende a outra, eu falo.

C. - Eu lembro que até a G. [refere-se à uma paciente com deficiência visual] queria ver onde que ela tava, como que ela tava... (...)

V. - Ã-hã. É que hoje eu não tô mais [nesta fase], sabe? Com essa questão de melhorar tem como lidar, mas eu tô tentando. Até chegar a hora de eu vir só aqui, igual vocês [em regime ambulatorial]. [Risos]

K. - Ela vai conseguir. Todo mundo conseguiu essa fase, essa fase que cê tava melhorando, fortalecendo, depois cê vem mais no grupo, vira sócia. [Risos]

Terapeuta (para V. e Vi.): Tá vendo? Vocês estão sendo convidadas pra se tornarem sócias do nosso grupo.

[Sorrisos. Breve silêncio.]

V. - Posso fazer uma pergunta?

Terapeuta: Pode.

V. - [voltando-se para K.] Como que foi o começo da recuperação da K.? (...)

K. - A minha [recuperação] também foi difícil porque eu não aceitava comer nada, nem tomar água, porque eu achava que a água engordava. Então pra mim foi muito difícil. Eu não dormia à noite, tinha medo de engordar. Então eu peguei síndrome do pânico também, então foi muito difícil pra minha família e pra mim, principalmente, porque eu não encarava a realidade. Então quando eu criei... eu queria o mundo das anorética, que só tinha importância o meu mundo, nada do que tava ao redor de mim tinha importância. Então eu fui vendo que eu estava assim desfalecendo, desmaiando demais. Então eu não queria morrer, porque eu tinha medo de morrer, só que eu também não queria comer. Aí eu peguei, aceitei o tratamento assim, tomando o soro. Primeiro eu fui partindo pro soro, falei: "Pelo menos não vai nada no estômago". [convém lembrar que nessa sessão a paciente V. estava com sonda nasogástrica, o que normalmente desperta reações desagradáveis em algumas pessoas.]

\footnotetext{
* Esse encontro foi audiogravado e transcrito de forma literal, depois de obtido o consentimento de todas as participantes.
} 
V. - Dieta?

K. - Dieta. E soro mesmo, glicose. Aí depois eu peguei... mas não foi aqui na USP, foi num hospital perto da minha casa, pelo convênio, aí eu peguei, fui aceitando aos poucos, mas foi muito difícil. Aí eu peguei, vim pra USP pra tratar. Aí aos poucos eu fui... eles foram colocando alimento assim. Eu lembro das profissionais que me ajudaram, aí eu fui engordando, virando aquela baleia...

V. - Que cê não imaginava...

K. - Que eu não imaginava. Eu dormia magra e acordava gorda, rolando na cama. Então hoje eu tô comendo e tô mantendo o peso. É lógico que a gente vai comer, vai chegar um peso que pára de funcionar [o tratamento], só que o mais difícil é controlar a nossa mente, porque, igual eu tava lendo, e eu tava pensando, refleti bastante essa semana, o nosso recurso, o grande ápice da doença, o iceberg, é o seguinte: a gente não sabe enfrentar os nossos problemas. A gente tenta fugir dos nossos problemas. Então a gente poderia ser uma alcoólatra, como qualquer outra coisa, mas a gente refugiou na anorexia. Então é um mundo só nosso, totalmente escondido, pai e mãe não sabe. Quando descobrem, parece que levou uma facada pelas costas e eles acabam não entendendo o que a gente sente. Pra eles são difícil, mas pra gente... eles têm que ver que pra gente também é difícil comer, se alimentar. A gente vê a comida não com tanto prazer igual eles vêem. Hoje eu já vejo a comida com prazer, eu como, não... eu tenho dificuldade ainda de comer arroz e feijão.

B. - Eu também.

Observa-se que o grupo se abre para acolher as novas pacientes, sobretudo V., que vira o centro das atenções. Essa paciente empreende uma busca ativa de informações, tirando proveito da experiência anterior de internação das demais para situar-se em relação ao tratamento. É interessante observar a atitude ativa e curiosa que ela sustenta ao longo das interações, o que contrasta vivamente com o quadro absolutamente regressivo com que chegou ao hospital. Além do nível crítico de desnutrição em que se encontrava, apresentava distúrbios de conduta e total descontrole dos impulsos. Essa paciente deu entrada no serviço "presa" em uma cadeira de rodas, com as mãos envoltas em ataduras. Os profissionais que a encaminharam tiveram que recorrer a esse recurso como forma de contenção, uma vez que ela, de forma compulsiva, enfiava toda a mão na garganta para induzir o vômito. Mostrando-se extremamente dissocia$\mathrm{da}$, a paciente justificava seu gesto auto-agressivo como uma tentativa de "tirar algo ruim de dentro de si”.

A conversação grupal prossegue com o clima de intensa auto-revelação exercitada pela paciente K.:

K. - Eu tenho medo de arroz e feijão. É um bicho de sete cabeças pra mim, mas eu como uma caixa de bombom. É isso que eu não entendo. Assim, o bombom tem mais caloria, mas eu não como arroz e feijão. Igual, eu comi três barras de chocolate; o arroz e feijão eu não como. Mas eu como batata frita, eu como manga, como fruta, mas eu recuperei bastante peso. Não estou mais com risco, mas a família tende a querer te ajudar e de vez em quando atrapalha, mas também, vamo dizer assim, se você não tem o apoio da família naquelas horas tristes... porque muitas vezes eu chorava... tinha dias que eu chorava e falava que eu tava inchando de repente, engordando. Me dava um desespero assim, eu tinha que tomar remédio e ficava chorando ou senão tinha que ir pro hospital tomar remédio e dormir, porque eu achava que eles já tavam me engordando, ficando gorda assim, caindo as pelanca no chão, pensei que eu ia morrer. Então me dava taquicardia, hipoglicemia, mas foi difícil, mas agora, graças a Deus, eu tô conseguindo!

O grupo pode ser utilizado como um espaço para obter esclarecimentos sobre as peculiaridades do transtorno alimentar. Informar-se pode ser uma importante via para adquirir um sentimento de domínio sobre si mesmo, como se pode apreender da seqüência interacional abaixo.

V. - Eu posso fazer um pergunta pra uma pessoa que já foi bulêmica (sic)?

D. - [oferecendo-se para responder] Eu!

V.- Existem períodos de anorexia e bulimia?

D. - É.

Manoel: Alternados, né.

D. - Pelo menos pra mim.

V. - É que eu tenho fases de anorexia, que eu tenho mais, e bulimia...

D. - Eu já cheguei a ficar internada por causa disso.

Manoel: Ano passado, né, D.? 
D. - É. Eu não queria ficar aqui, tava sem esperança também, sabe? Agora eu não preciso mais ficar aqui. É só cortar os vômitos.

O grupo também é um espaço de cuidado: não apenas o cuidado de si, mas também o cuidado do outro. Uma verdadeira escola onde se aprende a cuidar com palavras.

[Entra G., dez minutos após iniciado o grupo.]

Manoel - Oi, G.

K.- Ah, G. Que bom!

[breve silêncio]

K. - Estamos felizes em te ver! Já tava preocupada!

G..- [ri]. Não, eu fui resolver hoje.

C.: Hum.

G.: Fui tirar uma radiografia...

C.: Parece que cê já tá melhor.

Na sequiência abaixo pode-se verificar a negociação dos significados construídos por essas pacientes em torno da experiência de "estar doente"/estar em tratamento. No exemplo que se segue, é possível perceber o movimento do grupo de intercambiar diferentes sentidos que podem ser atribuídos à internação:

V. [a paciente recém-internada, lidando pela primeira vez com a necessidade de ser mantida em hospitalização integral]: Cê já chegou a ficar internada muito tempo?

C.: Não, não, não. Não internei. Fiquei assim, de ter desmaiado, de ter passado mal por algumas coisas...

K.: Ficar em observação vinte e quatro horas, sair e voltar...

C.: Mas eu nem tava tratando aqui ainda. Eu acho que é mais por causa disso.

Terapeuta: Outras pessoas que estão aqui e que têm experiência de internação poderiam responder pra V. o que sentiram?

G.: Eu tive vários tempos, várias vezes. Hoje eu tô sendo internada. Tô com medo, não tô querendo ficar.

C.: Perde o medo, G., cê tem que se preparar.

G.: (...) Eu tenho assim, já seis anos de HC. (...) a última internação eu tava um tempão, que foi pra fazer a gastrostomia, pra por a sonda no estômago.

V.: Mas o pior é quando cê chegou aqui, não é, na primeira vez?
G.: Foi. No começo eu sofri muito mais, assim, eu cheguei aqui com dezoito quilos. Assim, até eu descobrir que eu era doente demorou muito. Depois o trabalho de pôr a sonda no nariz demorou muito. No começo eu não queria aceitar, não aceitar que eu tinha anorexia, tal, que era doença da cabeça e eu falava que não era, que o problema era no estômago, queria criar - que eu já não tinha forças - que eu tava com câncer no estômago, que eu comecei a vomitar, que esses vômitos são espontâneos, no começo. E assim, custou muito, fiquei muito internada aqui, fiquei direto, tive meu filho e fiquei internada. Então assim, tenho muito medo. O meu pavor é falar que eu vou internar. [nesse momento está visivelmente emocionada] Eu tô... fico tremendo...

V.: Eu também não me dou muito bem com a internação, sabe? (...)

G.: Deixa eu te perguntar, cê tá internada?

V.: Eu tô.

G.: Já faz tempo?

V.: Faz.

C.: G., a gente tava aqui o dia que ela chegou. Foi no dia do nosso retorno. Lembra que ela chegou chorando assim...

G.: Ah, sim, sim, sim. Tá, tá. Lembro, lembro de você comentar.

C.: Isso.

G.: Assim, eu também tô assim apavorada de ficar hoje. Tá tudo arrumado em casa, tá tudo arrumado, tenho quase certeza absoluta que eu vou internar, né. Tá difícil aceitar, tem hora que eu aceito, assim... (...)

G.: Eu tô muito apavorada.

V.: Eu falo assim pra quem cuida de mim, porque tem muitos médicos que cuida da gente, né.

G.: É.

Na última fala de V. observa-se o efeito tranqüilizador que parece ter a percepção de disponibilidade da equipe ("tem muitos médicos que cuida da gente”). O suporte percebido funciona como alento e contenção para as emoções geradas pela perspectiva de hospitalização iminente da paciente G. Assim, notase uma curiosa transformação do papel assumido por V., a paciente nova que até então solicitava ativamente o apoio das pacientes veteranas para superar os temores desencadeados por sua primeira internação hospitalar. Essa paciente desloca-se para uma posição de quem tenta oferecer conforto e alívio para a experiente G.. - veterana não só do grupo como tam- 
bém de internações, mas que mesmo assim se revela como alguém que está "amedrontada" e "tremendo de medo".

Em um outro momento do grupo, nota-se que, em vez de mecanismos de identificação serem suscitados pela percepção das similaridades das experiências vividas no enfrentamento do transtorno alimentar, prevalece o reconhecimento das diferenças individuais:

D.: É. Eu não queria ficar aqui, tava sem esperança também, sabe? Agora eu não preciso mais ficar aqui. É só cortar os vômitos.

V.: O meu problema é esse. O meu problema é... que fica mais atrapalhando na minha internação é isso. É eu superar o medo de acabar de comer e não falar assim: "Eu vou lá no banheiro e vomitar", porque eu tô tentando achar forças pra não ir [ao banheiro]. Eu falo assim: "Não, essa comida tem que parar no meu estômago e ela tem que me fortalecer. Ela tem que me tirar disso."

C.: Eu pensava assim que eu parei de vomitar no primeiro dia... começo de dezembro, final de novembro, até porque de vez em quando eu vinha aqui no grupo, né, na maioria dos grupos, eu terminava de... a principal hora era a hora do café da manhã que eu não conseguia segurar, até porque era a hora que eu tentava comer mais, né.

K.: (...) Faz mais de um mês que eu não provoco vômitos, mas eu tô comendo. Mas eu [ainda] soco o dedo na garganta. Eu não venço completamente, não.

V.: A diferença é que o meu [vômito] vem espontaneamente.

A paciente V. revela seu esforço, ainda que malogrado, de obter o autocontrole ("eu tô tentando achar forças pra não ir [ao banheiro]"). Essa fala suscita a manifestação de K. que declara: "Faz mais de um mês que eu não provoco vômitos", que assume um caráter de apoio aos esforços empreendidos por V., ao mesmo tempo em que revela uma percepção das próprias dificuldades na manutenção desse "controle" conquistado arduamente: "Mas eu [ainda] soco o dedo na garganta. Eu não venço completamente, não." Essa atitude de K. admitir parcialmente o próprio fracasso em dominar seus impulsos ("vencer completamente") leva V. a se posicionar frente à K. sustentando sua diferença: "A diferença é que o meu [vômito] vem espontaneamente”.
O grupo alterna, assim, os movimentos de busca da identificação e diferenciação. Esse movimento pendular aparece de forma bem evidente na seqüência a seguir:

V.: Aí vai, fala pra mim como que é eficaz a alimentação. É muita... aquele negócio que passa pela sonda...

G.: A dieta.

V.: É, é muita dieta e eu não tô conseguindo fazer, sabe, de medo da dieta, de engordar, sabe? Só que eu já tô pegando peso porque tô evitando mais os vômitos, não tô tendo mais vômitos. Só assim, só de saber que eu tô... a minha família mora muito longe, é difícil deles me ver. De ter gente que tá te entendendo, né. Aqui cê tem gente que te entende mais do que lá.

K.: Isso.

V.: Aí a colega do lado [refere-se a uma paciente internada com síndrome do intestino curto] fala assim: "V., você tá perto de tudo o que você tem lá fora. Tenta se alimentar, deixa alguma coisa no estômago. Que importa se você vai ficar gorda ou se você não vai! As pessoas tem que gostar de você do jeito que você é." Então isso tá mudando a minha cabeça, sabe? Devagar. Aí hoje chegaram e falaram assim, até que eu ia melhorar, que eu quero manter o meu compromisso, os alimentares assim, entendeu? Tô voltando no retorno, já tô melhorando da área de risco do coração. (...) Internei com vinte e oito quilos. Por isso mesmo o meu coração tava parando de bater e elas tão me ajudando bastante, sabe? Só que às vezes o desespero é tanto, tanto, pra você sair dali logo, que você quer fazer tudo duma vez, sabe?

G.: Se quer melhorar assim faça ginástica, pega uma varinha de condão com a força.

K.: Cê precisa da força da sua mãe, da sua família também. Eu acho assim que a família ajuda bastante nessa hora. Por mais que os médicos tão juntos ali, não é a mesma coisa que a família. Mas eu acho assim, continua lutando, continua dando conta, não vai no banheiro, que cê consegue sair dessa, com certeza. Várias saíram e todas nós vamo sair. Todas aqui melhoraram já. E você tá entrando pro grupo agora, cê vai ver.

V.: Eu já tenho tentado falar com a família, essa situação. Irmão, eles falam um monte de coisa, chamam a gente de louca.

K.: Eu não tenho esse problema! [Risos, pois sabem que ela é filha única.] 
V.: Eu sei que é os irmão...

K.: Frescura, né. Minha mãe falava que era frescura.

V.: Meu namorado falava assim pra mim: "Ai, você vomita porque você quer". Não era uma coisa assim que eu sabia, mas pra ele podia ser porque eu queria. Mas a...

G.: Pra você já não.

V.: Já era mais forte do que eu.

C.: Parece que a pessoa fala isso, já te obriga a... parece que é a sua personalidade que tem que comer e vomitar.

V.: É.

K.: A gente tem muito isso. Mas assim, a gente é muito pressionada também. Querendo mudar o seu modo assim de comer e vomitar, porque depois acaba virando um estilo de vida. Mas eu sei que a gente muda esse estilo de vida e a cabeça da gente, porque a gente se sente muito pressionada. Parece que a gente tem aquela obrigação: "Pô, eu tenho que comer e não posso vomitar". Cê fica se vigiando até uma hora que cê não agüenta, cê corre pro banheiro.

V.: É. É assim mesmo.

K.: Aí parece que cê fica mais ansiosa, aí cê come de novo, vomita de novo. Quanto mais pressão, mais eu vomitava. Agora que eu não tenho pressão, eu não...

V.: É que nem no meu caso: eu, se eu fico preocupada eu vomito, se eu fico feliz eu vomito, se eu fico... [Risos]

Nota-se, nessa última fala, que V. é capaz de reconhecer a influência de seu estado emocional sobre a apresentação do sintoma. Essa percepção contrasta com sua crença, anteriormente relatada, de que os vômitos se manifestam "espontaneamente", dando a entender que são eventos absolutamente arbitrários, que não obedecem a nenhuma "causa" ou lógica identificável.

Destacaremos agora uma seqüência interacional em que é possível identificar claramente a percepção de melhora:

K. (...) graças a Deus, eu tô conseguindo! Eu tô fazendo terapia e a terapia tem me ajudado bastante, eu tenho conversado bastante com a minha mãe, meus familiares. Eles tão me compreendendo, eles não tão me obrigando a comer além daquilo que eu quero comer, que eu acho assim, não adianta obrigar ninguém a comer. A gente tem que pôr o que a gente quer. E hoje eu vejo assim, que a minha mãe tá mais serena, meu esposo tá mais sereno, porque eu passei aquele risco de vida que eu estava. Mas, em primeiro de tudo, a gente tem que achar força na gente, porque não existe doença crônica, existe pessoa crônica, porque eu tenho a doença há quinze anos. Falaram que não tinha mais jeito. (...) a recuperação agora vem a cada dois meses. Pra mim é uma vitória.

V. [tosse]: Desculpa. [tosse novamente]

K.: Tá sem ar, fica assim... [breve silêncio] Mas pra mim foi muito difícil encarar a realidade de tudo o que eu passei. Assim, pra mim é difícil até falar. [com a voz embargada]

Terapeuta: Tanto que você se emociona, né? [percebendo que os olhos de $\mathrm{K}$. se encheram de lágrimas]

K.: Emociono. Tipo assim, a gente passou por muita dificuldade, minha mãe não tinha onde ir, eu vivia em cima da cama, a minha vó tinha que cobrar pra mim comer. Meu pai me rejeitava, meu pai já tinha outra família. Eu fui internada duas vezes por causa de uma pessoa tentar me abusar sexualmente. Então foram coisas assim que começaram a ficar marcadas na minha vida...

A experiência inaugural de V. em termos de hospitalização desencadeia em K. lembranças que permitem que ela se reconecte com algumas vivencias emocionais que ficaram "marcadas na sua vida". Essas reminiscências de um passado doloroso propiciam, inclusive, que K. se recorde das razões que, segundo ela, motivaram suas internações anteriores. A emoção que vem à tona cria um contexto de experiência emocional corretiva, na medida que ela pode se dar conta de que está em um outro momento de seu existir e que, graças ao acolhimento que encontra no grupo, pode ressignificar o valor emocional de algumas experiências traumáticas do passado.

K. Então foram coisas assim que começaram a ficar marcadas na minha vida, tanto é que pra mim namorar foi muito difícil pra mim, me relacionar com alguém. (...) Mas passei por crises, que eu era gorda, eu pesava setenta e três quilos, eu tinha onze anos e era rejeitada também na escola. [fala muito emocionada] Então são coisas assim, que eu era discriminada pela minha família e pela sociedade, então ficou muito difícil pra mim. Então eu me refugiei nesse mundo da anorexia, en- 
tão eu não encarava mais a realidade. Quer dizer que é um mundo fora da realidade onde tem uma... cê acaba não acreditando: "Ah, isso é bobeira". Mas a minha vida assim, contando assim, eu passei várias dificuldades, tô tentando superar todas, pra um dia olhar pra trás e falar: "Não! Passou. Eu não vou sentir mais dor, só sentir aquilo que ficou pra trás".

Tanto no trecho acima como no que segue abaixo, oriundo de um outro momento do encontro em questão, observa-se que a percepção de melhora se estende para além de uma simples remissão de sintomas:

C: (...) [dizendo que está mudando] ...agora não. Gosto muito mais da comida.

K.: Eu ficava muito longe da comida. Pelo menos antes eu ficava muito longe da comida. Parecia lavagem. Eu sentia que tava me dando ânsia, que não me dava vontade nem de chegar perto.

\section{C.: Eu não conseguia sentir o gosto bom de nada} assim.

V.: Eu também não. E assim, quando eu como, eu como às pressas, sabe? Eu não consigo me, assim, adaptar com o alimento, sentir o alimento, sabe?

K.: Eu acho assim, uma coisa que melhorou pra mim: eu tento colocar pouca comida no prato pra não ficar aquela coisa muito grande, dar uma garfada e mastigar bastante. Mastiga bastante, até sair uma aguinha. Engole, conversa um pouquinho, dá outra garfada. Aí cê vai distraindo com a outra pessoa, na hora que cê perceber cê já acabou o prato. E você não come com tanta compulsão, pra depois você ir logo no banheiro e vomitar. Pelo menos pra mim ajudou bastante. Comendo assim, fracionado.

Em primeiro lugar, salta aos olhos a troca de experiências que o grupo promove, na medida em que as pacientes contam para as demais as estratégias de enfrentamento que adotaram e que se mostraram eficientes no controle dos sintomas. Além disso, revelase a percepção de algumas de que mudou também a relação com a vida. Então não se trata apenas de voltar a "sentir [o gosto] do alimento", mas de recuperar o sabor da vida e readquirir a alegria de viver, de "sentir o gosto bom" da vida.

O grupo parece, assim, facilitar o trabalho de (re)ativar as forças curativas da personalidade, ao abrir a possibilidade de se usufruir uma experiência de encontro com o outro que seja sentida como significativa e nutritiva para a paciente. É dessa maneira que o grupo pode se tornar um grupo "comestível" para as pessoas que se encontram ali em busca de novas possibilidades de dar sentido às suas vidas. Isso fica bastante evidente na seqüência interacional a seguir:

K. (...) Eu acho que esse peso tá bom. Hoje eu tenho variado entre cinqüenta e um e cinqüenta e cinco quilos. Eu não esquento a cabeça mais, assim, tanto com o peso mais. Se eu passo dos cinqüenta e cinco, aí sim eu faço uma dieta e começo a comer tudo diet, light. Chegou nos cinqüenta e dois, cinqüenta e três, volto a comer normalmente. Eu não vou engordar de um dia pro outro. Não é oito ou oitenta e acabou. A gente tem que, assim, apreciar a vida. É tão bom! Igual sábado, eu fui na casa da minha prima. Eu tentei subir no pé de mangueira pra comer manga. É a coisa mais gostosa assim é você tá conversando com alguém e compartilhando aquilo com alguém. É um momento assim que eu gosto de tá comendo e compartilhando com os outros. Aquele ventinho fresco no seu rosto em cima da árvore, pendurada, e eu não gosto nada de criança! Eu já tô meia velha, mas eu tava lá brincando. Foi ótimo pra mim. No domingo eu não pensei nem em caloria, nem se a manga ia me engordar. Eu não pensei. Cheguei em casa, fui fazer a minha alimentação, depois, à noite, eu lembrei: "Eu comi e não pensei que eu ia engordar". É uma vitória, ou seja, eu passei um dia já sem pensar em comida, assim, que eu ia engordar. Já é uma vitória, pelo menos pra nós todos, tirar que eu vou engordar. Consegui tirar o medo da comida. Agora eu falei pra minha mãe até: "Eu não vou engordar". Eu vou ficar magra mesmo comendo. E é assim, cada um tem uma história. A minha experiência de vida é essa que eu posso passar pra você.

Manoel: Foi importante, né, você poder dizer isso, porque quando cê falou da mangueira, que tá redescobrindo o prazer de se alimentar com outras pessoas e tem um prazer de compartilhar... eu fiquei pensando que esse grupo aqui é uma espécie de mangueira em que a gente sobe e vai compartilhar com as outras pessoas aquilo que tá acontecendo com a nossa vida. A K. pôde trazer aqui a história de vida dela, seus altos e baixos, como ela disse, mas sobretudo como hoje está podendo dis- 
por disso, tomar tudo isso na mão, como a fruta, e saber que quem dirige a sua vida é você.

K.: Isso! Não é a doença!

Ao resgatar a lembrança de um momento prazeroso em que foi possível "gostar de tá comendo e compartilhando com os outros", K. pôde reatualizar (e, possivelmente, repotencializar) os efeitos transformadores dessa experiência com as companheiras do grupo, transformando-as em comensais, ou seja, naquelas novas partícipes de uma vivência compartilhada de reencontro com o gozo de se alimentar.

Essas potencialidades transformadoras que assinalamos dependem, evidentemente, da disposição para conviver com a diversidade que cada participante introduz no espaço grupal. Isso é o que tempera a interação grupal. Poder tirar proveito da pluralidade de vozes e olhares é um dos ingredientes essenciais nessa mistura que o grupo constitui. O terapeuta nesse contexto tem uma presença discreta e não-intrusiva, marcada pela escuta atentiva e pelo uso absolutamente parcimonioso de intervenções verbais. Não assume um papel de destaque, não é o chef, mas apenas um administrador da "cozinha", que acompanha os movimentos evolutivos do grupo e intervém, de maneira sóbria e pontual, caso seja necessário (por exemplo, se a cozinha começa a "aquecer" muito, ou se, ao contrário, está muito fria). Acompanhante discreto, monitora o andamento do trabalho do grupo o tempo inteiro. Sua atitude é tipicamente de holding, de continência para a sustentação do processo grupal. Fornece acolhimento na medida suficiente e estritamente necessária. Quando julga pertinente, intervém atribuindo às experiências compartilhadas um significado construtivo. Apesar de adotar uma postura não-intervencionista, está atento ao tempero, cuidando para que as diversas misturas se façam na dosagem e no seu tempo apropriado de cozimento.

As pacientes são as verdadeiras gourmets do grupo. A tarefa primordial das "cozinheiras" é encontrar o "ponto" ideal que permite ao grupo alcançar seus objetivos sem lentificar nem apressar demasiadamente a fervura. A culinária requer um bom domínio da técnica do bom cozinhar, mas é, antes de tudo, arte e paixão. O preparo de cada prato (encontro) é único. O modo peculiar como as diferenças individuais vão se combinar e se mesclar parece catalisar o potencial mutativo contido em cada encontro - no qual é gerado, de maneira compartilhada, o fruto da transformação.

\section{6- CONSIDERAÇÕES FINAIS}

Pacientes com transtornos alimentares vivem uma condição crônica limitante e isso tem uma expressão na existência dessas pessoas. Do ponto de vista existencial, somos nosso corpo. Portanto, a maneira como vivemos a relação com nosso corpo expressa os limites e possibilidades de nossa identidade.

No grupo de pacientes percebemos que os participantes vão se envolvendo uns com os outros ao se dedicarem à arte de cuidar dos demais. É a partir da descoberta de que é capaz de cuidar-do-outro que o paciente começa a se perceber como alguém que também pode cuidar-de-si-mesmo, aprimorando essas habilidades no sentido de desenvolver o auto-respeito e uma maior sensibilidade às próprias necessidades emocionais. O grupo torna-se, então, o celeiro de novas possibilidades de cuidar de si, fazendo com que pacientes que normalmente são vistos como incapazes de tomar conta de sua própria vida possam se especializar na produção de víveres que alimentam a mente e fecundam o espírito.

Nos exemplos fornecidos, vimos que as pacientes envolvidas no encontro grupal perceberam que podem se associar e tirar amplo proveito dessa associação, beneficiando-se da atitude cooperativa e solidária. Perceberam que podem entrar em contato e comunicar ao outro suas demandas afetivas de uma maneira eficiente e evoluída. Perceberam que podem se influenciar mutuamente trocando informações qualificadas em vez de intermináveis lamentações. E que podem compartilhar soluções que encontraram em suas buscas pessoais e que deram certo, produzindo alívio e conforto emocional.

Nessa medida, entendemos que o grupo é um "laboratório" de relações e soluções humanas para problemas humanos, uma autêntica lavoura experimental onde se cultivam sementes de esperança, inauguram-se novas fontes de vida e edificam-se pontes que conectam ao desconhecido-que-ainda-não-pôde-serpensado - ou seja, a dimensão inconsciente que envolve o grupo, caldo nutritivo e húmus essencial de onde provém à experiência emocional.

Ao aproximarem-se desse desconhecido, dentro dos limites seguros de um contexto protegido constituído de "pares", um encontro esperançoso pode se produzir. Nele as pessoas com sofrimento mental aprendem com a experiência compartilhada, desenvolvem os recursos de criatividade que as levam a se reconectar com o solo primordial que é a experiência corporal e descobrem que um novo mundo é possível. 


\section{AGRADECIMENTOS}

Este artigo é dedicado ao Prof. Dr. José Ernesto dos Santos e à Profa. Dra. Rosane Pilot Pessa Ri- beiro, com profunda gratidão por compartilharem muitos dos conceitos aqui discutidos e por manterem viva a paixão pela assistência combinada com a investigação científica.

Santos MA. Misery and hope: support group for patients with eating disorders. Medicina (Ribeirão Preto) 2006; 39 (3): 386-401.

ABSTRACT: The author presents his experience as a psychotherapist of a group of patients who were diagnosed as having eating disorders in special anorexia and bulimia. This therapeutic support group is part of a multi-professional approach carried out in the ambulatory of eating disorders which has been assisting people since 1982 in the Clinical Hospital of the Medical School of Ribeirão Preto, University of São Paulo. The participation in the group is open to both sexes, although the majority of participants are young single women, with diverse socio-economic backgrounds. The conceptual framework of the intervention follows psycho-dynamic formulations. The non recognition of the psycho-pathological condition, the psychiatric co-morbidities and the feelings of not trusting the relationships are the therapeutic challenges to be overcome in order to establish the needed therapeutic alliance between the patient and the health professional. The psychological intervention aims to sensitize these patients for their need of treatment, stimulating self awareness about their problem and a responsible attitude regarding health care. The support offered has an educational intention besides its socio-emotional care. The therapeutic group process seems to facilitate the construction of favorable conditions for changes supporting an experience exchange space and an attitude of mutual help. This attitude has increased the sense of union and the group cohesion. Indeed, the cumulative experience over the last years have shown that peer groups promote re-signification of beliefs, values and feelings regarding to one's own body and the process of self-care reflecting in the positive reduction of symptoms of the eating disorders. Concluding we argued that the conduction of the psychotherapy should prioritize the re-establishment of the prime attachment to life.

Keywords: Anorexia Nervosa. Bulimia Nervosa. Psychotherapy, Group - Support.

\section{REFERÊNCIAS}

1 - Bruch $H$. Eating disorders, obesity, anorexia nervosa, and the person within. New York: Basic Books; 1972.

2 - Bruch $\mathrm{H}$. The golden cage: the enigma of anorexia nervosa. Cambridge (MA): Harvard University Press; 1978.

3 - Kovács MJ. Morte e desenvolvimento humano. São Paulo: Casa do Psicólogo; 1992.

4 - Albom M. A última grande lição: o sentido da vida. Trad. JJ Veiga. Rio de Janeiro: GMT/Sextante; 1998.

5 - Scivoletto S, Segal A, Castilho SM, Cordás TA. Anorexia nervosa e bulimia: como diagnosticar e tratar. Rev Bras Med 1995; 52: 132-142.

6 - Bechelli LPC, Santos MA. Psicoterapia de grupo: noções básicas. Ribeirão Preto (SP): Legis Summa; 2001.

7 - Zimerman DE, Osorio LC. Como trabalhamos com grupos. Porto Alegre: Artes Médicas; 1997.
8 - Zuckerfeld R. Psicoterapía de la obesidad. Buenos Aires: Letra Viva; 1979.

9 - Fiorini H. Teoria e técnica de psicoterapias. Rio de Janeiro: Francisco Alves; 1984.

10 - Vinogradov S, Yalom ID. Manual de psicoterapia de grupo. Trad. D Batista. Porto Alegre: Artes Médicas; 1992.

11 - Bechelli LPC, Santos, MA. Psicoterapia de grupo e considerações sobre o paciente como agente da própria mudança. Rev Latino-Am Enfermagem 2002; 10 (3): 383-91.

12 - Bechelli LPC, Santos MA. Psicoterapia de grupo: como surgiu e evoluiu. Rev Latino-Am Enfermagem 2004; 12 (2): 242-9.

13 - Bechelli LPC, Santos MA. O paciente na psicoterapia de grupo. Rev Latino-Am Enfermagem 2005; 13 (1): 118-25.

14 - Bechelli LPC, Santos MA. O terapeuta na psicoterapia de grupo. Rev Latino-Am Enfermagem 2005; 13 (2): 255-61. 
15 - Bechelli LPC, Santos MA. Transferência e psicoterapia de grupo. Rev Latino-Am Enfermagem 2006; 14 (1): 110-7.

16 - Kaplan HI, Sadock BJ, eds. Compêndio de psicoterapia de grupo. Trad. JOA Abreu, D Batista. 3. ed. Porto Alegre: Artes Médicas; 1996.

17 - Zimerman DE. Fundamentos psicanalíticos: teoria, técnica e clínica - uma abordagem didática. Porto Alegre: ArtMed; 1999.

18 - Zimerman DE. Fundamentos básicos das grupoterapias. 2. ed. Porto Alegre: Artes Médicas; 2000.

19 - Motta LF, Santos MA, Souza MLP. Grupoterapia breve de múltiplos casais em hospital-dia. Paidéia 2002; 12 (22): 6981

20 - Oliveira EA, Santos MA, Mastropietro AP, Picini VS, Bueno CC, Matos RN, Voltarelli JC. Grupo de apoio ao familiar do transplantado de medula óssea. Rev SPAGESP 2003; 4: 5262.

21 - Santos MA. Percepções de pais acerca de uma experiência em grupo de apoio a adotantes: uma construção sistêmica. Rev SPAGESP 2004; 5: 29-36.
22 - Santos MA, Oliveira EA, Moscheta MS, Ribeiro RPP, Santos, JE. "Mulheres plenas de vazio": os aspectos familiares da anorexia nervosa. Vínculo: Rev NESME 2004; 1: 46-51.

23 - Santos RK. Anorexia nervosa na adolescência: concepções sobre a evolução do transtorno, o tratamento e suas repercussões psicossociais. [Monografia], Ribeirão Preto: Faculdade de Filosofia, Ciências e Letras de Ribeirão Preto - USP; 2000.

24 - Castro FM. Mães de adolescentes portadores de anorexia nervosa: Percepção da doença e dos fatores familiares envolvidos. [Monografia], Ribeirão Preto: Faculdade de Filosofia, Ciências e Letras de Ribeirão Preto - USP; 2000.

25 - Santos MA. O trabalho em grupo na instituição hospitalar: acompanhamento psicológico de apoio ao familiar. Rev. SPAGESP. 2002; 3: 68-73.

26 - Santos RK, Mouraria CG, Soares IVB, Prizanteli CC, Bighetti F, Godoy RSP, Ribeiro RPP, Santos MA. Grupo de apoio psicológico aos familiares de portadores de anorexia e bulimia nervosa. Rev SPAGESP 2002; 3: 139-43. 